\title{
Prevention of aerosol dissemination in Orthopaedics while reaming or drilling during COVID 19 pandemic - A technical note
}

\section{Dr. Yuvarajan P}

Ortho One Orthopaedic Centre, Coimbatore, Tamilnadu, India

Dr. Surya Prakash Naidu Paila ( $\nabla$ dr.suryaprakashnaidu@gmail.com )

Ortho One Orthopaedic Centre, Coimbatore, Tamilnadu, India https://orcid.org/0000-0001-9154-2777

Dr. Navya Chalumuri

Ortho One Orthopaedic Centre, Coimbatore, Tamilnadu, India

Dr. Rajshekhar

Ortho One Orthopaedic Centre, Coimbatore, Tamilnadu, India

Dr. David V Rajan

Ortho One Orthopaedic Centre, Coimbatore, Tamilnadu, India

Method Article

Keywords: Coronavirus, COVID 19, Aerosol, Orthopaedic Surgery, Reaming

Posted Date: July 20th, 2020

DOI: https://doi.org/10.21203/rs.3.rs-44594/v1

License: (9) This work is licensed under a Creative Commons Attribution 4.0 International License.

Read Full License 


\section{Abstract}

SARS-CoV-2 / COVID 19 is the largest health emergency and a global pandemic of recent times. Orthopaedic surgery involves procedures involving routine reaming and drilling the bones that generate substantially high volumes of aerosols and microdroplets creating a huge concern among the operating surgeons, anaesthetists and the supporting staff. We aimed at reducing the amount of aerosol generation and microdroplet spread by a simple and cost-effective technique which can be very well reproducible by anyone, thereby reducing the infection/viral load.

\section{Introduction}

2019 Novel Coronavirus /COVID 19 has spread globally affecting the entire health care system. The guidelines given by World Health Organization and Centers for Disease Control and Prevention for respiratory aerosol-generating procedures (AGPs) such as intubation during COVID 19 was clear which includes the use of a mask (preferably FFP3 or P3) mask and face protection. ${ }^{1,2}$ However, the recommendations for surgical AGPs, such as the use of high-speed power tools in the operating theatre, was not clear. The current recommended PPE for orthopaedic surgeons by various authors include level 4 surgical gowns, FFP2-3 or N95-99 respirator masks, face shields or airtight goggles and double gloves. ${ }^{3,4}$ Use of surgical helmets with surgical face shields may not be the solution in this scenario due to a thin permeable top for air intake. ${ }^{3,4}$ However, there is a high cost involved and limited availability of these devices at present.

The spread of SARS-CoV-2 is predominantly via droplets/aerosols, but also via direct contact with contaminated surfaces. ${ }^{5}$ Both these modes have to be considered while taking personal prophylaxis. Furthermore, one needs to consider the viral load to which the health worker is exposed which in turn directly influence the severity of the disease if acquired. ${ }^{5,7}$ Most of the orthopaedic surgical procedures involve the use of surgical power tools, such as electrocautery, bone saws, reamers and drills which are shown to produce aerosols/droplets. ${ }^{5,10}$ It has been postulated that virus transmission can happen through blood aerosol infecting the health care professionals. ${ }^{6,10}$ We describe the current practice that we have adopted to reduce aerosol production and dissemination while treating patients surgically.

\section{Technique}

We used surgical face shield (Sterishield fig.1) to prevent aerosol while reaming for proximal femur (proximal femoral nailing), midshaft femur (intramedullary interlocking nailing) and supracondylar femur fractures (supracondylar nailing). The surgical face shield was placed over the operative area as a barrier for aerosol dissemination. First we marked a circle over the centre of the surgical face shield measuring about $15 \mathrm{~mm}$ in diameter and cut into a ' + ' shape as shown (Fig. 2). The face shield is then placed over the surgical site for reaming or drilling (Fig. 3,4 ) and the reamer can be advanced in and out through the portal made over the face shield. This prevents the dissemination of aerosols that are generated while 
power reaming and drilling. We found this to be an effective way of reducing the viral load which further reduces the infection risk.

\section{Discussion}

Surgical face shields are worn as routine personal protective equipment (PPEs) by the surgeons during joint replacement surgeries to prevent periprosthetic joint infections. Each surgical face shield costs around 1100 INR to 1800 INR and to be worn by everyone in the operating team, further burdening the healthcare system. These surgical face shields prevent the operating team from aerosols/microdroplets to some extent.

The filtration material of surgical face shield is in standards with ASTM F2100 Level 1 which signifies that the sub micron particulate filtration efficiency at 0.1 micron is $\geq 95 \%{ }^{7}$

However, the supporting staff and anaesthetic team are at high risk for infection by aerosols. As per the guidelines developed by the INTERNATIONAL CONSENSUS GROUP (ICM) headed by Javad Parvizi surgical face shields are not recommended to use routinely for the unconfirmed cases during this pandemic, the reasons being the surgical helmets and fans in it can harbour viruses and they can't be sterilized regularly and in between the procedures. ${ }^{7}$ This acts as a potential source of infection from patient to surgeon and between surgeons and from surgeon to the next patient. ${ }^{8}$

ICM group also recommends the use of protective eyewear that provides a seal around the eyes (eg: goggles) along with a mask (preferably N95, FFP2 or P3 with expiratory valve) in the absence of surgical face shield. ${ }^{8}$

Furthermore, there is a huge gap in supply and demand globally due to COVID 19 pandemic. Because of the surge in demand and low availability in protective gear, new standard operating procedures should put forth to meet the crises. ${ }^{9}$

With the use of surgical face shields as a barrier directly over the surgical field as we described in our technique not only reduces aerosol dissemination contaminating the operating theatre but also costeffective further reducing the economic and social burden to the patient and healthcare system.

We have come up with this novel way to protect ourselves and our team members in these unprecedented times. The aim of this paper is to share our technique with other orthopaedic colleagues and help them and their teams to stay safe.

\section{Conclusion}

This technique is easy, cost-effective, reproducible and can be tailored as per the need and site of surgery. Our technique will reduce aerosol dissemination and operation theatre contamination. However, this technique can be used as an adjuvant to the routine use of personal protective equipment (PPEs). 
Highlighting safety as priority and prevention is better than cure, this small innovation will greatly help in the fight against COVID-19 pandemic.

\section{Declarations}

\section{Declarations:}

Conflict of Interest: The authors declare that they have no conflict of interest.

Funding: There is no funding source.

Ethical approval: Institutional Ethical committee approval has been obtained by the authors.

\section{References}

1. World Health Organization. Infection prevention and control precautions for aerosol-generating procedures. Available at https://wWw.who.int/csr/disease/coronavirus_infections/IPCnCoVguidance_06May13.pdf

2. The Centers for Disease Control and Prevention. Interim Infection Prevention and Control Recommendations for Patients with Suspected or Confirmed Coronavirus Disease 2019 (COVID-19) in Healthcare Settings. Available at https://www.cdc.gov/coronavirus/2019-ncov/hcp/infectioncontrol-recommendations.html

3. Howard RA, Lathrop GW, Powell N (2020) Sterile field contamination from powered air-purifying respirators (PAPRs) versus contamination from surgical masks. Am J Infect Control 48(2):153-156. doi: 10.1016/j.ajic.2019.08.009

4. Hirschmann MT, Hart A, Henckel J, Sadoghi P, Seil R, Mouton C. COVID-19 coronavirus: recommended personal protective equipment for the orthopaedic and trauma surgeon. Knee Surg Sports Traumatol Arthrosc. 2020 Apr 27:1-9. doi: 10.1007/s00167-020-06022-4.

5. Vishwanath $A$, et al. Working through the COVID-19 outbreak: rapid review and recommendations for MSK and allied health personnel. J Clin Orthop Trauma. 2020 Mar 26. doi:

10.1016/j.jcot.2020.03.014. 
6. Raghavan R, Middleton PR, Mehdi A. Minimising aerosol generation during orthopaedic surgical procedures-Current practice to protect theatre staff during Covid-19 pandemic. J Clin Orthop Trauma. 2020 May-Jun;11(3):506-507. doi: 10.1016/j.jcot.2020.04.024.

7. ASTM F2100-19e1, Standard Specification for Performance of Materials Used in Medical Face Masks, ASTM International, West Conshohocken, PA, 2019. Available at www.astm.org

8. Parvizi J, Gehrke T, Krueger C, Chisari E, Citak M, Van Onsem S et al. Resuming Elective Orthopaedic Surgery During the COVID-19 Pandemic. J Bone Joint Surg Am. 2020;00:1-8. doi:

10.2106/JBJS.20.00844

9. Standard Operating Procedure (SOP) for Extended Use of N-95 Masks for Personal Safety of Health Care Workers (HCW) at AIIMS Order Vide No. F.79/COVID19/2020-Extt.(H.)

10. Basso T, Dale H, Langvatn H, Lønne G, Skråmm I, Westberg M, Wik TS, Witsø E. Virus transmission during orthopedic surgery on patients with COVID-19 - a brief narrative review. Acta Orthop. 2020 May 14:1-4. doi: 10.1080/17453674.2020.1764234.

\section{Figures}




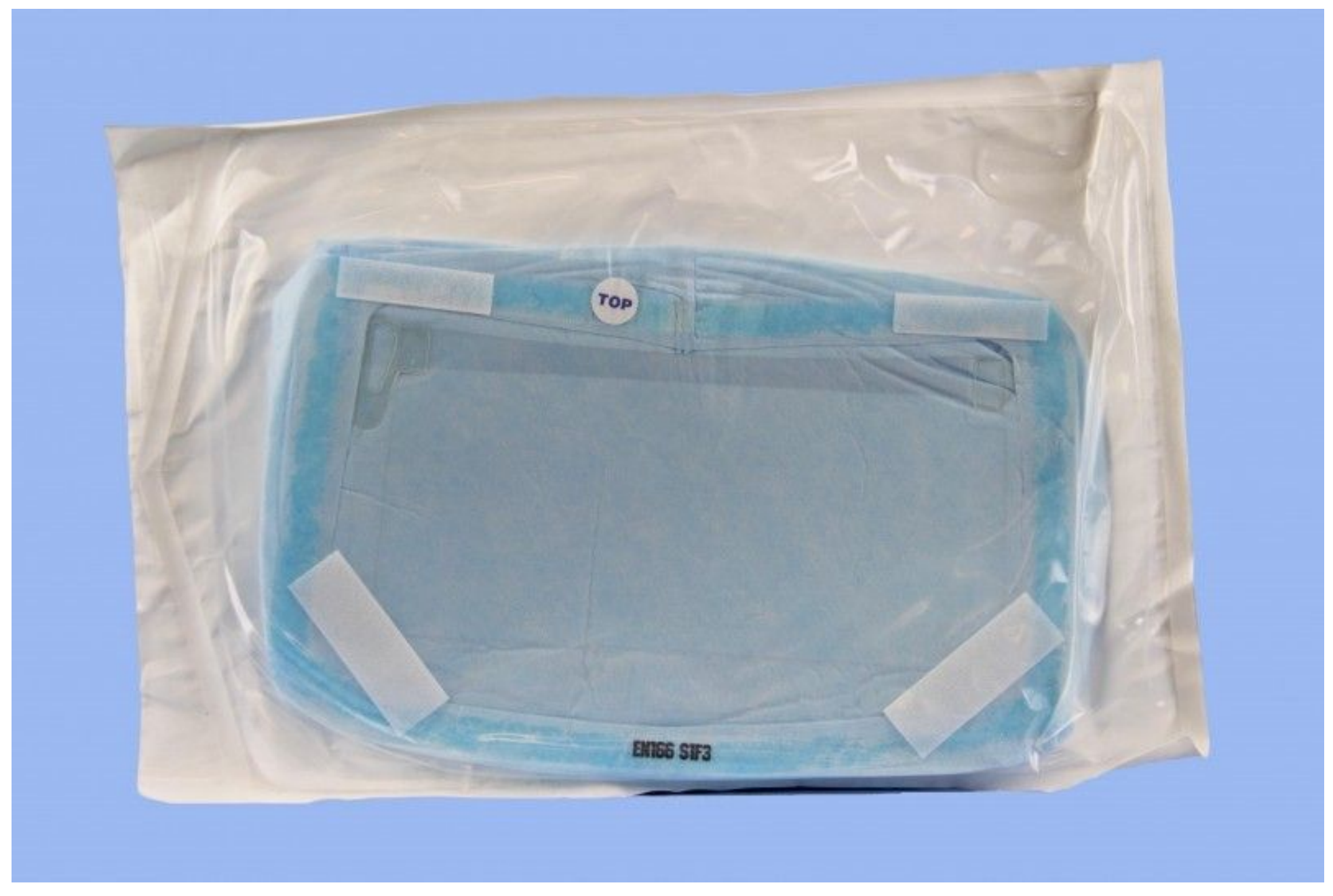

Figure 1

Sterishield 


\section{a}

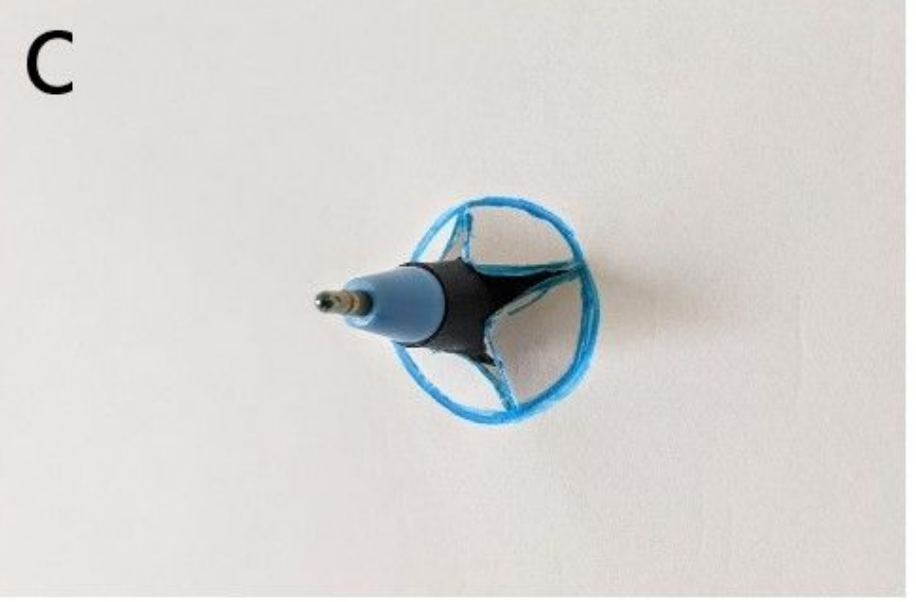

\section{d}

\section{b}
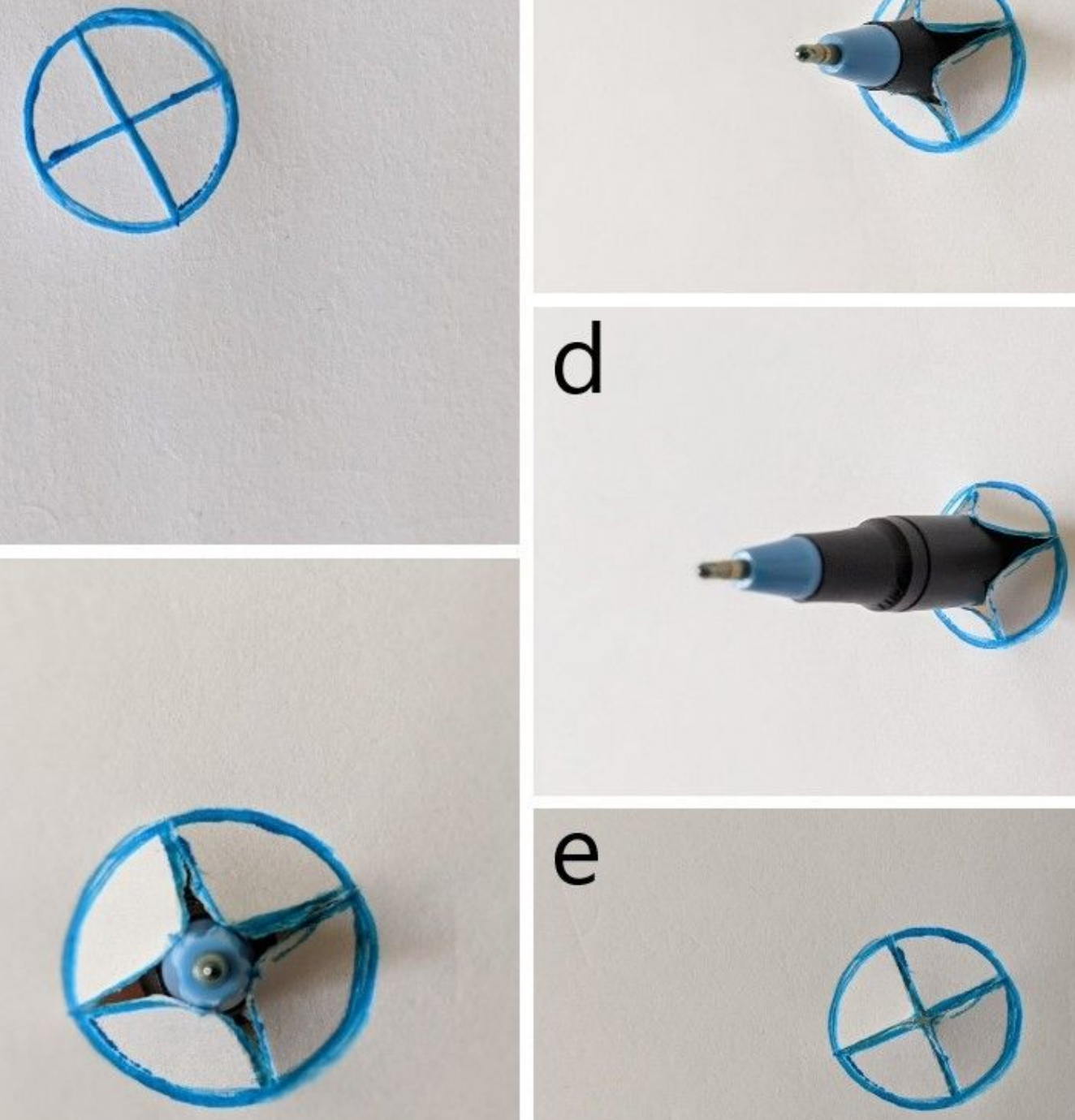

e

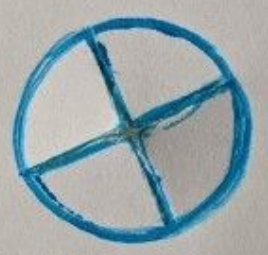

Figure 2

(2a- a circle of measuring $15 \mathrm{~mm}$ in diameter was drawn and cut into + shape as shown; $2 \mathrm{~b}, 2 \mathrm{c}, 2 \mathrm{~d}$ showing opening up of cut ends as we advance in; $2 e$ showing closing up of the cut ends as we take out the instruments.) 


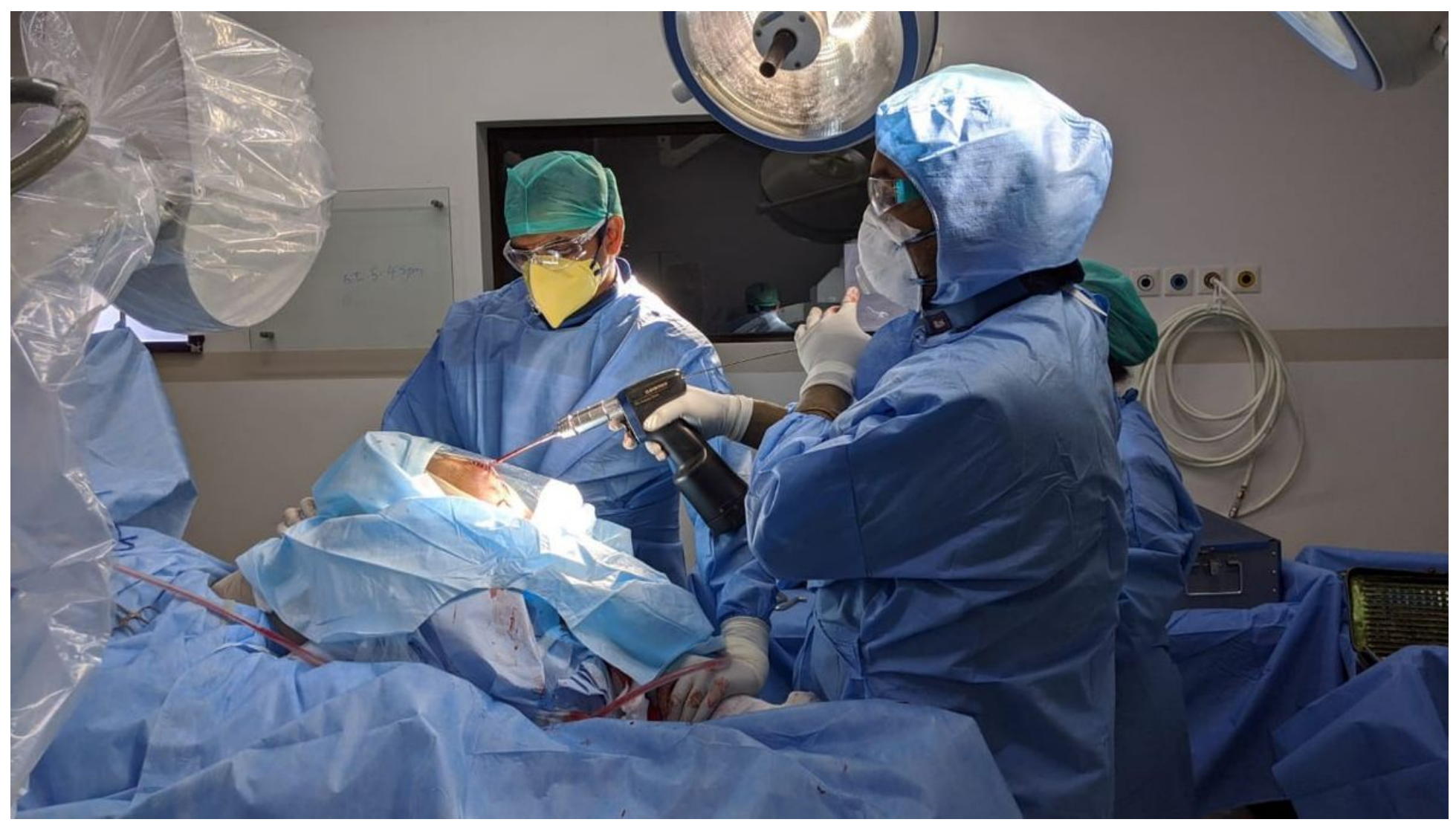

Figure 3

Use of surgical face shield as a barrier for aerosols while reaming for supracondylar femur fracture

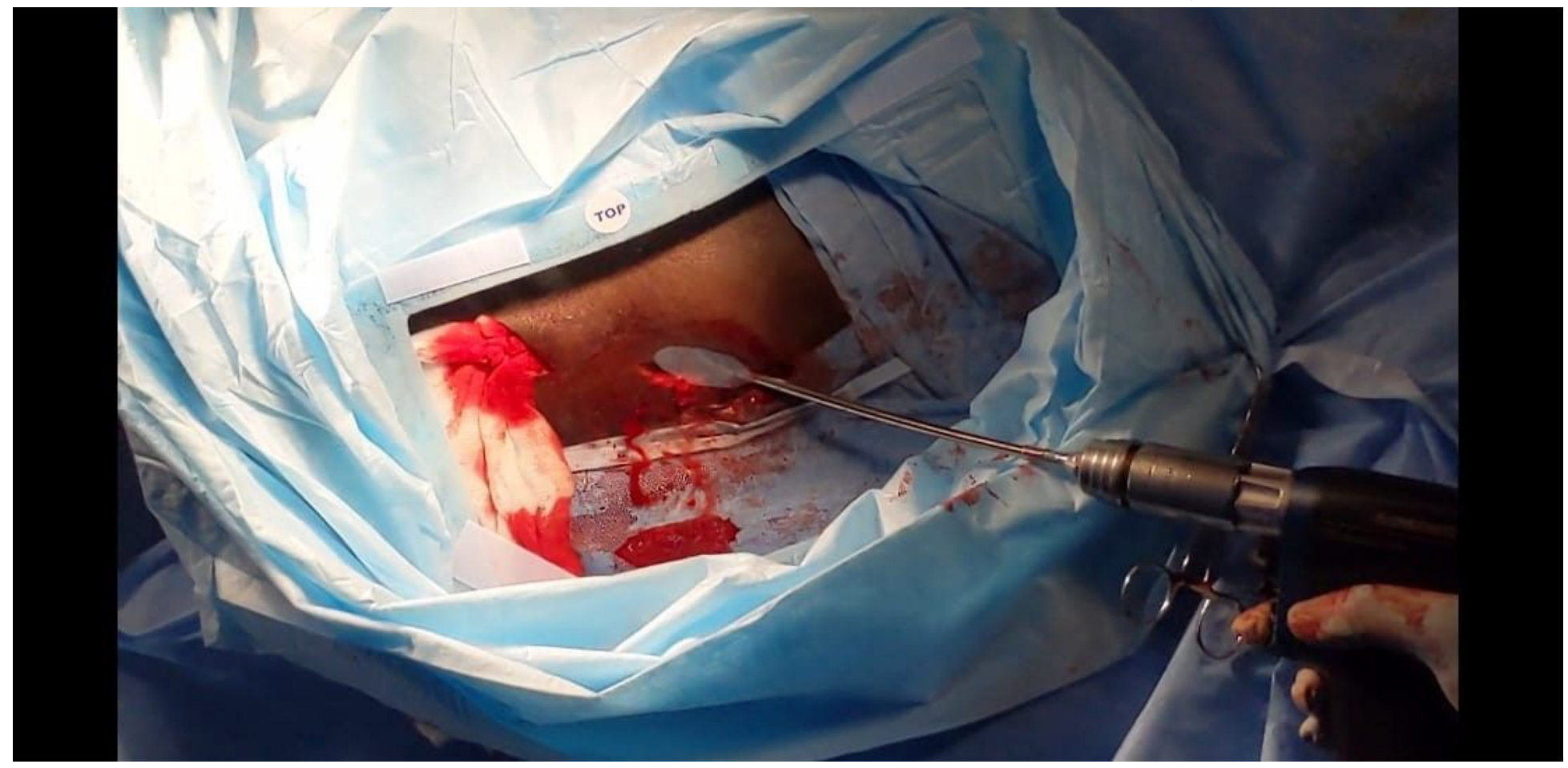

Figure 4

Use of surgical face shield as a barrier for aerosols while reaming for femur IM interlocking nailing 